\title{
Differences in Opportunities for the Disabled in England and Scotland: A Survey of Paraplegics in Scotland
}

\author{
RALPH H. JOHNSON, GILLIAN S. JOHNSON
}

British Medical fournal, 1972, 1, 779-782

\section{Summary}

The facilities available to disabled people living in Scotland were studied by visiting and interviewing a group of 50 paraplegics living in Glasgow and the surrounding counties. The degree of unemployment in the group $(74 \%)$ was far greater than has been reported in other surveys, and no quadriplegic was in remunerative employment. Though the general unemployment level in the area is high services to help the disabled gain employment were only partially utilized.

Liaison between social workers was not always successful. Some paraplegics were visited at home by both a medical social worker and a local authority social worker, while others were not supported by either. There was no apparent attempt by local authorities to identify the disabled, as is required in England under Section 1 of the Chronically Sick and Disabled Persons Act, 1970. Several paraplegics lacked facilities which are covered by Section 2 of the Act. The exclusion of Scotland from Sections 1 and 2 of the Chronically Sick and Disabled Persons Act may widen the differences between the two countries as the Scottish legislation is less specific.

\section{Introduction}

There has been a growing concern that the needs of the disabled have been neglected. This was a major factor behind the passing of the Chronically Sick and Disabled Persons Act, 1970. The scale of need was indicated in a recent survey of the handicapped and impaired, from which it was estimated that about $25 \%$ of all such patients were not receiving any services whatsoever (Buckle, 1971). In order to assess the situation in Scotland we surveyed a homogeneous group of people disabled with paraplegia. Paraplegics have a relatively static medical condition with clear disability and their mental processes are not affected.

We wished to determine the extent of facilities available to these patients. This could be of particular importance because not all of the sections of the 1970 Act apply to Scotland. Part of the study therefore examined whether or not the difference in legislation between Scotland and south of the border might give rise to less favourable provision of facilities in the area.

\section{Survey Procedure}

Fifty paraplegics living in the West of Scotland were visited and personally interviewed. The areas covered were the City of Glasgow and the counties of Lanark, Dunbarton, Renfrew, and Ayr. The names and addresses were obtained from several sources, including the Scottish Paraplegic Association and the records of Philipshill Hospital, Glasgow, and Edenhall Hospital,

\footnotetext{
University Department of Neurology, Institute of Neurological

Sciences, Southern General Hospital, Glasgow S.W.1

RALPH H. JOHNSON, D.M., D.PHIL., Senior Lecturer and Consultant

Glasgow University, Glasgow W.2

GILLIAN S. JOHNSON, B.A., DIP.SOc.STUD., Department of Social Administration and Social Work
}

Musselburgh, although many of the subjects had not been treated initially at these hospitals. Paraplegics were included if they were over the age of 16 years, had left hospital after initial treatment, and were living at home. A sampling technique could not be applied as there is no complete register of the disabled in the area, and we did not wish to use social work department lists as these would relate to those who had applied for social services.

The interviews were informal and were based on a questionnaire drawn up after two pilot interviews. The questionnaire, which was completed at the time of interview, was designed to allow information to be standardized. Freedom was given for individual comment, however, and it was hoped that the subjects would talk widely about their circumstances.

Most of the paraplegics (44 males and 6 females aged 16 to 62 years) were under 40 years of age. Forty-four had suffered traumatic lesions of the spinal cord, three had become paraplegic after spinal operations for cervical disc or tumour, and three had other medical conditions with a static neurological lesion of the spinal cord and no other neurological dysfunction; one of these had a congenital paraplegia and two had lesions which were probably vascular. All had been paraplegic for at least a year and 34 had been paralysed for less than 10 years. Seventeen had cervical lesions, 25 had thoracic lesions, and 8 had lumbar lesions. Altogether 37 had complete and 13 had incomplete lesions, the latter causing severe disability. The most common lesion was at the lower thoracic level and was complete. One man with a lower thoracic incomplete lesion was able to walk with the aid of callipers and crutches, but all the others relied on wheel-chairs.

\section{Results}

\section{EMPLOYMENT}

Before disablement most of the 50 paraplegics were in paid employment (37) and only one man was unemployed. Most of the working group were manual workers. The effect of disablement on the pattern of employment was considerable, leaving only seven paraplegics working. There were, in addition, four students and two women who were housewives able to run their homes unaided. Thirty-seven subjects were unemployed (Fig. 1). Of those who were working four had the same type of occupation

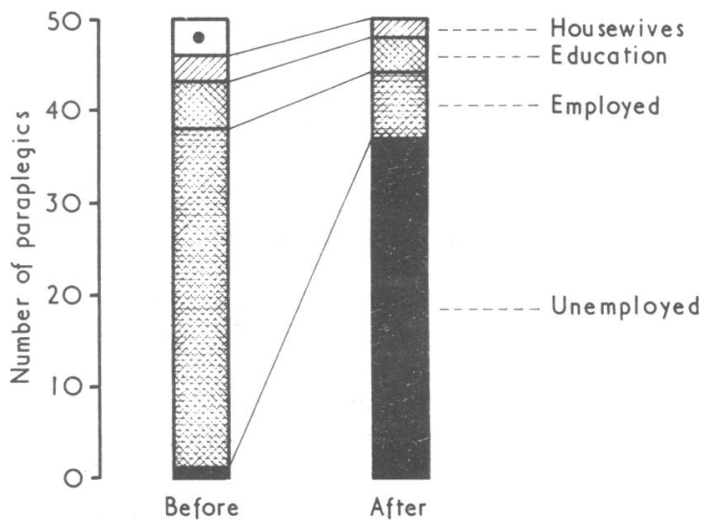

FIG. 1-Occupations before and after disablement. $=$ Military service (3), preschool child (1). 
as before disablement and were professional and skilled workers. Two paraplegics were in sheltered employment. Not all of the unemployed paraplegics were seeking work. Several said that they did not wish to work and seven were physically unfit. There were, however, 13 paraplegics who had unsuccessfully tried to obtain employment, and of these six had cervical lesions. No patients with cervical lesions were in employment.

Altogether 44 paraplegics were potentially employable when discharged from hospital. Four found work for themselves and 21 had been in contact with a disablement resettlement officer from the Department of Employment (Fig. 2). The contact was frequently limited as the resettlement officer could offer little

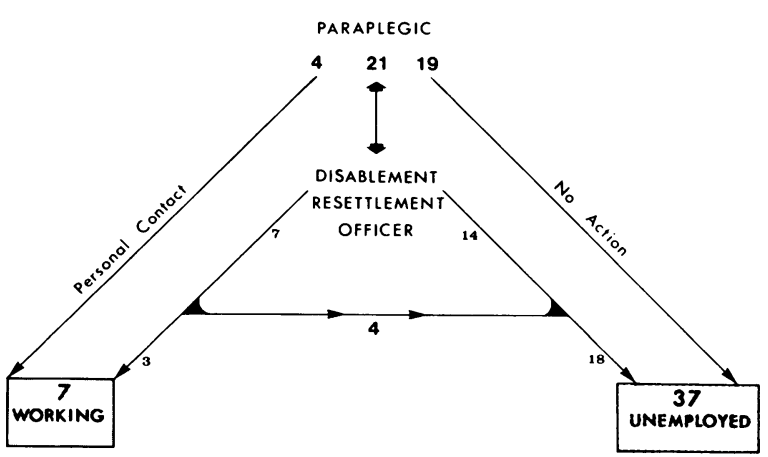

FIG. 2-Contact of 44 potentially employable paraplegics with disablement resettlement officers.

hope of employment in the area. Nineteen paraplegics were never referred to a disablement resettlement officer. Of the seven who found work through the resettlement officer, four resigned at an early stage and only one remained in the job obtained for him. The others gave medical reasons for leaving or complained that the work offered was unsatisfactory or badly paid.

Eight paraplegics were offered industrial rehabilitation. Six attended a course and two refused the offer (see Table). Those

Rehabilitation Made Available to the Paraplegics and its Effect on their Employment

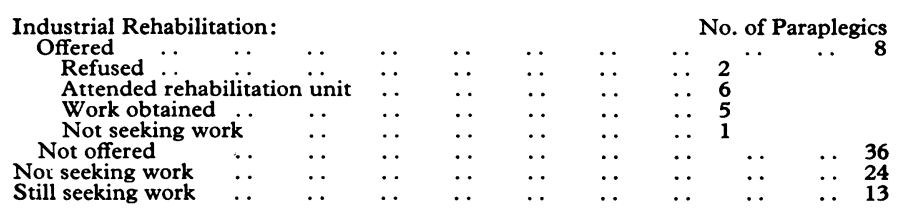

who received industrial rehabilitation were males under 25 years of age at the time of injury, and most had experienced some form of training and were skilled workers. Three of them later undertook retraining. Two-thirds of the subjects not offered rehabilitation (23), however, stated that they did not want to work. Thus in the total group of potential workers there were 13 who were trying to obtain work, 10 of whom had never had a chance of rehabilitation.

\section{CONTACT BETWEEN SOCIAL WORKERS AND PARAPLEGICS}

During their period of hospital treatment 49 paraplegics were seen by a medical social worker (Fig. 3). Only one paraplegic did not see a medical social worker as he was nursed at home. Forty-one paraplegics were visited at home by a local authority social worker. Thirteen were visited by the medical social worker after they had been discharged from hospital and 10 of them were in contact at home with both social workers. Thus three paraplegics saw only the medical social worker at home and six had no contact with any social worker once they had left

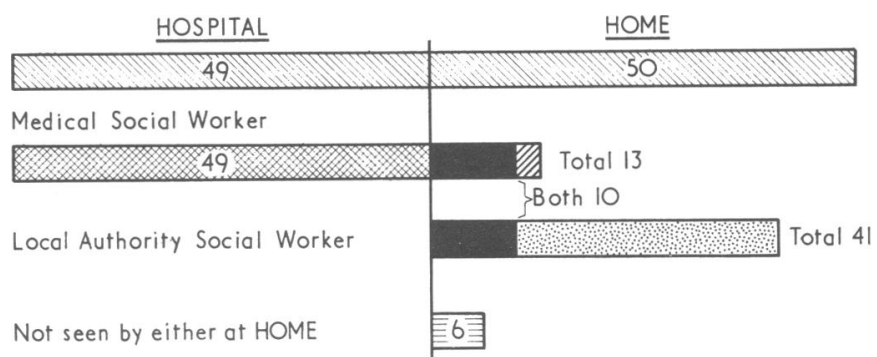

\section{VISITS BY SOCIAL WORKERS}

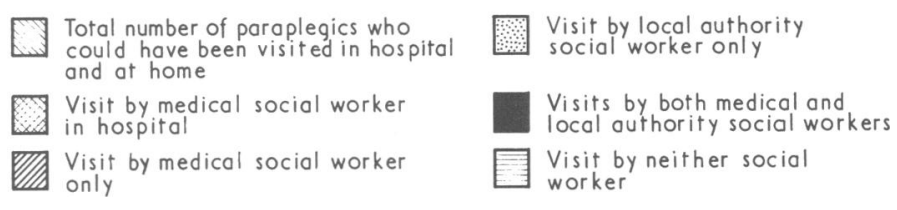

FIG. 3-Contact between social workers and paraplegics in hospital and at home. Central vertical bar divides visits in hospital (left) from those at home (right).

hospital. In addition, five of the paraplegics received regular visits from their general practitioners. No paraplegic was visited in hospital by a local authority social worker although several families were contacted by their local authority before the patient's discharge in connexion with rehousing and home adaptations. Only seven paraplegics received a routine introductory visit from a local authority social worker on arrival home from hospital. Others were visited at their own request to discuss house adaptations and aids. Often the paraplegics had regular contact with a local authority social worker while arrangements were made for house alterations but no further visits once the work was completed. On no occasion did a medical social worker and a local authority social worker visit a paraplegic's home together. Only eight said that they were still contacted periodically. One young paraplegic who had worked as a miner before his injury had additional contact with the coal industry's social welfare organization, whose social worker visited regularly.

\section{SERVICES AVAILABLE TO THE PARAPLEGIC AT HOME}

Many paraplegics already had one or more of the facilities specified under Section 2 of the Chronically Sick and Disabled Persons Act but there were some cases of need (Fig. 4), and there was little evidence that local authorities were going to help in this regard. The most noticeable inadequacy was in the

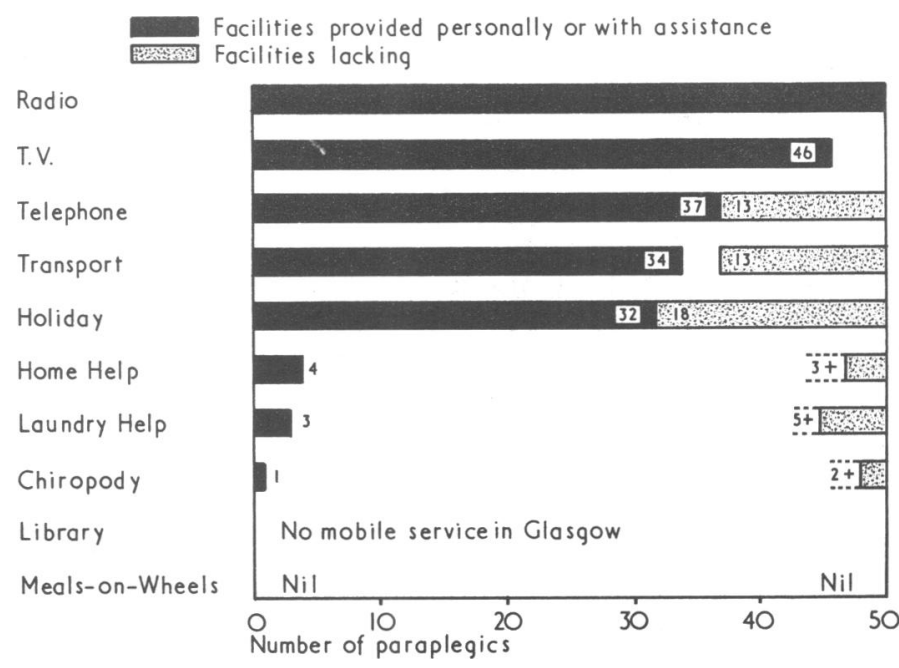

FIG. 4-Provision of facilities covered by Chronically Sick and Disabled Persons Act, 1970. 
provision of telephones; 13 had no telephone, and some of these were alone in their homes. Thirty-four paraplegics had either an invalid vehicle or an adapted car. Three others lived with a car-owner but 13 paraplegics had no form of transport readily available to them. We found no evidence of local authorities providing transport services in accordance with Section 2 (d) of the Act. Some paraplegics (11) had been on holidays arranged by welfare or voluntary organizations, but 18 others had not been away, mainly because of cost. Many of the subjects were not aware of accommodation for the disabled offered by local authority holiday homes or of published information on holidays for the physically handicapped. The assessment among the paraplegics of other needs which were not covered was more difficult (Fig. 4). A number of paraplegics, besides those indicated in Fig. 4, might have benefited from some services if they had been more widely available.

\section{HOUSING AND HOUSE ADAPTATIONS}

Thirty-five paraplegics had moved house because of their disability; 14 had made the change privately and 21 through their local authority. Despite these changes there were still a number of paraplegics whose homes were inadequate. Seven had an upstairs bathroom and W.C. to which they had to be carried, and one family had no bath. Two paraplegics had their beds in the living room as this was the only ground-floor room. Four could not leave their homes unaided because of front-door steps too steep to be ramped. In all other cases local authorities had helped with aids and interior alterations to a great extent, and these appeared to be adequate.

\section{Discussion}

The present group of paraplegics was very similar to other groups studied elsewhere in respect of age, sex distribution, cause of injury, and frequency of spinal lesions (Guttmann, 1965, 1967; Gehrig and Michaelis, 1968; Thompson and Murray, 1967). It therefore appeared justifiable to compare their social adaptation in terms of employment, rehabilitation, and the availability of practical support.

There was a pronounced difference between the employment statistics of our series and those of similar groups of paraplegics reported on elsewhere. Guttmann (1962) analysed patients who had been discharged from the National Spinal Injuries Centre at Stoke Mandeville, Buckinghamshire, and found that $66 \%$ of all paraplegics were employed; this included some in further education and in part-time occupations. In 1965 and 1967 he amplified these findings and reported that if he discounted patients who had retired and were over age, or who were under treatment in hospital, physically unfit, or dead, then only $14.6 \%$ were not working at all. The figure in the present series was $60 \%$.

We found even more remarkable differences when we examined the problem of employment of quadriplegics. None in our group, which included nine complete and eight incomplete lesions, was working, although one was receiving further education. In a study of 188 quadriplegics discharged up to 1968 from Stoke Mandeville, Robinson (1970) found that $44 \%$ were in remunerative employment and $7.4 \%$ were students. A survey carried out at the Institute of Rehabilitation Medicine, New York University Medical Center, on 131 quadriplegics aged 18 to 60 years who had been patients between 1962 and 1967 disclosed that $34 \%$ were employed and $47 \%$ were receiving higher education (Siegel, 1969).

The poor employment situation that we have found in the West of Scotland is related to a local unemployment rate above the national average. Nevertheless, it could also be related to poor facilities, such as provision of transport, compared with more prosperous areas. The figures also indicate that many paraplegics were not referred to a disablement resettlement officer and few were offered industrial rehabilitation. Moreover, those who did use these services were generally dissatisfied with the type of work offered. Unemployment could be preferable to a badly-paid, low-status job, as the sentiments expressed by a 23-year-old man suggested-"I spent three years learning a trade, being an apprentice and going to night school. Now they ask me to spend the day sticking labels on bottles."

Studies elsewhere have shown similar situations. Robinson (1970) found that only 11 out of 84 employed quadriplegics had obtained work through the disablement resettlement officer and only two had received rehabilitation. A recent survey of work and housing for the disabled in Great Britain showed that out of 146 unemployed who sought help from the disablement resettlement officer five obtained work through this service (Buckle, 1971). The difficulties that the present group of paraplegics had over employment indicate the necessity of further development of the rehabilitation services. This may be achieved by the reorganization proposed by the National Advisory Council on the Employment of the Disabled, under whose proposals resettlement work will be a full-time duty requiring training.

In the U.K. the passing in 1970 of the Chronically Sick and Disabled Persons Act highlighted growing concern that the needs of the disabled have been neglected. The sponsors of the 1970 Act explained in early debates that their aims were to make it possible for the handicapped "to participate in industry and society according to their ability" (Mr. A. Morris, M.P.). Sections 1 and 2 of the Act excluded Scotland, as it was suggested that the cover provided by these sections would be available as a result of the Social Work (Scotland) Act, 1968 (Section 12), the terms of which are far more general- "It shall be the duty of every local authority to promote social welfare by making available advice, guidance and assistance on such a scale as may be appropriate for their area. . .."

Under Section 1 of the Chronically Sick and Disabled Persons Act, which came into force on 1 October 1971, local authorities in England and Wales must assess the numbers and needs of chronically sick and disabled persons in their area and publicize the services which are available to them. This should provide the social services with a comprehensive register of disabled persons, which was not achieved under previous legislation. Our results indicate that many disabled people in Scotland may not be in touch with the social services. In the present group of 50 patients with a well-recognized disability six had had no contact at home, and many of the others were not being reassessed. Among these six patients there were obvious cases of need, even for simple measures like adaptations in the home. This failure could have been overcome if the patients had been automatically registered as disabled persons with their local authority at the time of leaving hospital, as should now be the case south of the border.

Only five received regular visits at home from their general practitioner, and it was therefore possible that general practitioners were not fully aware of their patients' problems. Similar difficulties were found in a study of the rehabilitation of 10 paraplegics discharged from the Liverpool Regional Paraplegic Centre (Forder, Reti, and Silver, 1969; Reti, 1969). That study was mainly concerned with co-operation between medical personnel in the National Health Service, and the authors concluded that many failures of communication resulted in frustration and hazards for the patients and their relatives. Automatic registration would prevent at least some of these problems.

Section 2 of the Chronically Sick and Disabled Persons Act makes provision for the disabled at home by requiring that local authorities consider the need for facilities in the home, including the following: (a) practical assistance in the home; (b) wireless, television, library, or similar recreational facilities; (c) lectures, games, outings, recreational facilities outside the home, and educational facilities; $(d)$ assistance in travelling to 
use services outside the home; (e) assistance with home adaptations; $(f)$ holiday facilities; $(g)$ meals at home or elsewhere; and (h) a telephone or any special equipment necessary for its use. This section, like Section 1, does not apply to Scotland. The Social Work (Scotland) Act, 1968 is obviously not providing similar support, and it remains to be seen how effective the 1970 Act is in England and Wales. Many of the facilities listed above were available but there were many patients in need. In normal circumstances $74 \%$ ownership of telephones would be high (the Family Expenditure Survey for 1968 showed only $29 \%$ of British households having this amenity (Department of Employment, 1971)), but Section 2 of the 1970 Act recognizes the telephone as an essential facility for the disabled. Perhaps the most significant indication of social deprivation is the difficulties over holidays and transport experienced by many in this series.

Problems such as these are to be found on a wide scale throughout Great Britain. From a survey of the handicapped and impaired in a quarter of a million households it was estimated that although three out of four drew on at least one service there remained 2,000 very severely handicapped and 90,000 others who were living alone and not receiving services (Buckle, 1971). A writer reviewing that survey found consolation in the Chronically Sick and Disabled Persons Act and commented that the situation shown in the report might soon be improved as a result of it (Lancet, 1971). We are concerned that improvement is less assured in Scotland, where the provision of these services is not guaranteed by legislation.

Other sections of the Act apply to Scotland. Section 3, for example, lays a new duty on local authorities to consider the particular needs of the chronically sick and disabled when planning the provision of housing. Special houses are to be distinguished in planning proposals. Such provision would be very useful, as local authority provision of purpose-built housing in the area covered by the present survey was very limited and none of the paraplegics occupied such accommodation.

In examining the social consequences of paraplegic in Scotland we have had the advantage of studying a group of patients with obvious disability. We would suggest that the difficulties in obtaining employment and social services may be greater for subjects with less clearly defined disability.

We thank the paraplegics for their co-operation and Miss G. Bowie for help with the survey. We also wish to thank Sister L. MacQueen, Miss M. Lloyd, and Mr. A. MacDougall (Philipshill Hospital, Glasgow). Mrs. M. Thompson (Edenhall Hospital, Edinburgh), and Mr. J. Laird (Scottish Paraplegic Association) for help. Mr. Duncan Guthrie and Professor J. A. Simpson gave encouragement, and I.B.M. (U.K.) Ltd. provided financial support.

\section{References}

Buckle, J. R. (1971). Office of Population Censuses and Surveys. Handicapped and Impaired in Great Britain, Part II. London, H.M.S.O. Department of Employment (1971). British Labour Statistics Yearbook, 1969, Table 194. London, H.M.S.O.

Forder, A., Reti, T., and Silver, J. R. (1969). Social and Economic Administration, 3,3 .

Gehrig, R., and Michaelis, L. S. (1968). Paraplegia, 6, 93.

Guttmann, L. (1962). Rehabilitation, 43, 9.

Guttmann, L. (1965). In Trends in Social Welfare, ed. J. Farndale, p. 319. Oxford, Pergamon Press.

Guttmann, L. (1967). Paraplegia, 5, 115.

Reti, T. K. (1969). Role and Communications in the Rehabilitation of Paraplegics Report for Liverpool Regional Hospital Board.

Robinson, E. S. (1970). Survey of Employment for Quadriplegics. National Spinal Injuries Centre, Stoke Mandeville Hospital, Aylesbury, Buckinghamshire. Privately circulated

Siegel, M. S. (1969). In Proceedings of 17th Veterans Administration Spinal Cord Injury Conference, New York p. 230. New York, Veterans Administration

Thompson, M. A., and Murray, W. A. (1967). Paraplegia at Home: A Pilot Survey. Edinburgh, Livingstone.

\title{
"Capillary Permeability" in Patients with Collagen Vascular Diseases
}

\author{
JANET MARKS, D. A. BIRKETT, SAM SHUSTER
}

British Medical fournal, 1972, 1, 782-784

\section{Summary}

"Capillary permeability" to serum albumin has been measured in patients with collagen vascular diseases by a method which compares the dilution of intravenously injected ${ }^{131} I-h u m a n$ serum albumin and ${ }^{51}$ Cr-R.B.C.S. The results indicate an increased capillary permeability comparable to that which occurs in patients with extensive inflammatory skin disease. We suggest that this increased capillary permeability may be the cause of the episodes of oedema which occur in patients with collagen vascular diseases such as disseminated lupus erythematosus, systemic sclerosis, dermatomyositis, polyarteritis nodosa, and rheumatoid arthritis. "Spontaneous periodic oedema" may be the presenting feature of collagen vascular disease and is due to increased capillary permeability.

University Department of Dermatology and Wellcome Laboratories for Research into Skin Disease, Royal Victoria Infirmary, Newfor Research into Skin Disea
castle upon Tyne NE1 4LP

JANET MARKS, D.M., M.R.C.P., Senior Lecturer

D. A. BIRKETT, M.B., B.CHIR., M.R.C.P., Consultant Dermatologist, Teesside, Darlington, and Northallerton Hospitals. (Present address: Carter Bequest Hospital, Middlesbrough)

SAM SHUSTER, PH.D., F.R.C.P., Professor of Dermatology

\section{Introduction}

People with disseminated lupus erythematosus, systemic sclerosis, dermatomyositis, polyarteritis nodosa, and rheumatoid arthritis may have oedema. This is not always explicable on the basis of heart failure, renal or hepatic involvement, hypoalbuminaemia, or treatment with fluid-retaining drugs, and it is not always limited to areas clinically affected by the disease process. It occurred to us that it might be due to increased "capillary permeability" as in patients with erythroderma, and we therefore set out to test this hypothesis.

\section{Patients and Methods}

Patients with various collagen vascular diseases were asked if they would agree to take part in the investigation. The diagnoses were made on the usual clinical and laboratory grounds. Although patients with disease of all degrees of severity were included, most of them were in hospital and therefore more than mildly affected; moreover, colleagues who knew of our interest in oedema may have tended to refer, particularly, albeit unconsciously, the oedematous patients to us. The patients who had unexplained oedema at the time of the investigation are indicated in Fig. 2 but a few of the remainder gave a history of one or more episodes of swelling in the past. The degree of oedema varied from a little bilateral ankle swelling to severe generalized oedema. No patients who had 